\title{
AN ANALYSIS OF THE EFFECT OF NON-PAYLOAD WEIGHT ON FUEL CONSUMPTION FOR A WIDE-BODIED AIRCRAFT
}

\author{
Enis T. TURGUT * \\ Aircraft Airframe and Powerplant Department, Faculty of Aeronautics and Astronautics, Anadolu University, \\ TR26470 Eskișehir, TURKEY
}

\begin{abstract}
Fuel flow rate of an aircraft varies significantly during a typical flight, mainly due to required engine thrust, speed, weather conditions, aircraft configuration and aircraft mass. Of these, the effect of aircraft mass, being the non-payload portion, on fuel flow is investigated in this study. The investigation is carried out for twin-engined wide-bodied aircraft, during its intercontinental flights. Based on actual flight data records, two approaches are developed, in which the fuel flow rate is estimated based on three independent variables; altitude, aircraft mass and flight speed. The regression models are found to be highly significant and average fuel consumption is found to be $2-3 \%$ of the non-payload mass per flight hour. It should be noted that this percentage is affected by flight altitude and aircraft initial mass, of which the latter has a greater effect. In addition, it is worth noting that when the aircraft initial mass increases, the fuel consumption percentage also tends to increase.
\end{abstract}

Keywords: Aircraft, Fuel consumption, Non-payload weight, Cruise altitude

\section{Nomenclature}

FF: Fuel flow $(\mathrm{kg} / \mathrm{s})$

TAS: True air speed (knot)

SD: Standard deviation

SR: Specific range $(\mathrm{NM} / \mathrm{kg})$

ULF: Uninterrupted level flight

\section{INTRODUCTION}

For a typical commercial aircraft, fuel is a major operational cost item. In addition, since the price of fuel generally tends to increase (in certain periods there can be considerable decreases as well, but usually only temporarily), it is therefore of great importance to maximize the benefits of burning each kilogram of fuel. There are certain actions (direct routing, taking advantage of wind) and strategies (better engines, lighter aircraft, sophisticated aircraft systems or alternative fuels) to minimize the fuel consumption of aircraft. Of these, perhaps one practical measure is to reduce aircraft non-payload weight as much as possible [1].

Aircraft manufacturers have been making great efforts to minimize the manufacturer's empty weight (MEW) of an aircraft. Regarding operational measures, there may still be a significant potential to provide fuel savings through weight minimization. For this purpose, one should consider operational items (e.g., passenger seats, galleys, all kind of fluids except fuel, fuselage paint, emergency equipment, aircraft documentation and other standard or customized items) and total fuel (trip, alternate, reserve, so on) which, in this study, are considered to be in the non-payload weight category.

The effect of a non-payload weight increase on fuel consumption was investigated by the aircraft manufacturer, Fokker [2] for its Fokker 50 and Fokker 70 turboprop model aircraft. It is reported that 
for an increase in aircraft mass of $100 \mathrm{~kg}$, the increment in block fuel per flight (each flight is assumed as 1.2 hour) can be between 1.0-2.1 kg (Fokker 50) and 2.5-4.5 kg (Fokker 70), depending of speed and altitude.

When a commercial aircraft is considered, in addition to the effects of weight increase, during long intercontinental flights, the initial weight of an aircraft decreases significantly, which leads to a considerable reduction in fuel consumption. Since this effect may be different for different aircraft types, in some studies lightening of the aircraft weight, along with fuel consumption, is not taken into consideration [3], while in others it is [4-6].

Since heavier aircraft tend to burn more fuel, the effect of aircraft initial weight on emissions is also of concern for the environmental impact perspective, and minimizing non-payload weight may also be important in reduction of aircraft emissions [7]. Although there have been few studies aimed at quantifying this effect, Duchene (2006) reports that a $20 \%$ increase in aircraft initial weight of an Airbus A320 results in $25-30 \%$ more emissions, depending on the emissions species. It is also noted that the effect is highly variable for different aircraft categories. In another study, the effects of aircraft take-off weight on ultrafine particle emissions [8] are investigated, and it is noted that a mean peak height of 15 $\mathrm{nm}$ particles increase slightly with aircraft weight.

In the light of previous studies, the effect of aircraft mass, being the non-payload portion, on fuel flow is investigated in this study. The investigation is carried out for twin-engined wide-bodied aircraft, during its intercontinental flights, using actual flight data records.

\section{MATERIALS AND METHOD}

In this study, twelve differently registered twin-engined wide-bodied commercial aircraft, of the same type, which had performed 126 intercontinental flights in 2014, are considered. There were two round trip routes, between Turkey and USA, with half of the flights being performed in January, whereas the other half were performed in August.

All of the aircraft and the engine parameters were obtained from actual flight data records (FDR). In a typical FDR system, numerous aircraft and engine data are recorded each second (in certain systems the frequency of the data may be up to 4 logs per second). This data can then be transferred into a .csv file for use in flight safety, condition monitoring or maintenance procedures. In this study, only certain parameters (altitude, flight path angle, true air speed, aircraft mass and fuel flow) during high level flight are used. The dataset is generated through running a set of Visual Basic Application codes on each FDR .csv file, rather than manually determining level flight. This is a lengthy and time consuming process, considering that there are 126 files with between 30,353 and 48,641 rows in each file.

The analyses focus only on high level flights, which will hereafter be called as uninterrupted level flight (ULF). In order to detect the high level flight, a control parameter is selected as 'flight path angle'. During climb, level flight and descent, this parameter is greater than zero, zero, and less than zero, respectively. The duration of each ULF in the dataset may be significantly different and range from several minutes to 21,500 seconds ( $~ 6$ hours). Half of the observations are lower than 24 minutes, whereas $28 \%$ of all of the observations is more than 1 hour. The extremely long UFLs presents useful study areas, such as investigation of the variation of fuel flow (FF) with aircraft mass or cruise altitude for a specific flight. However, when it comes to asserting an average FF at a specific altitude or aircraft mass, long ULFs might lead to inaccurate results since the variation of aircraft mass from the start and end of the ULF is too great to link an average aircraft mass with an average FF. In the relevant literature, there are studies in which reduction of aircraft weight, along with fuel consumption, has been taken into consideration [4-6], while in others these effects have been neglected [3]. However, in this study, this is considered and therefore, in certain analyses, a different approach is taken. Accordingly, all of the ULFs are divided 
into segments of which the ULF time is limited to 240 seconds. For instance, an ULF of 21,500 seconds can be divided into 89 segments with each segment having 240 seconds and the last segment having 380 seconds, due to the residual. With this approach, the average of total fuel burn in each segment can be calculated as $533 \mathrm{~kg}$ ( $\mathrm{SD}=92$ ), which shows it to be significantly close to normal distribution, with the weight variation at that level not affecting the fuel consumption tendency of the aircraft significantly. For comparison, if the ULFs had been treated as they are (not being divided into smaller segments), due to substantial differences between the observations, the average of the total fuel burn would have been found to be $3013 \mathrm{~kg}(\mathrm{SD}=3500)$. This may lead to a significant effect on the fuel consumption tendency of the aircraft.

A distribution of 240 seconds of ULFs per aircraft is given in Table 1. The dataset includes 15,680 observations and, since there are no low level flights below $28,000 \mathrm{ft}$ for at least 240 seconds, ULFs performed above $28,000 \mathrm{ft}$ of altitude are considered. However, since the number of ULFs at 28,000 ft is low, in many analyses the lowest ULF is selected as $29,000 \mathrm{ft}$. The highest ULF is $39,000 \mathrm{ft}$ with 120 observations, whereas the highest number of observations of 3319 is observed at $34,000 \mathrm{ft}$.

Table 1. The distribution of the number of level flights per aircraft

\begin{tabular}{lll}
\hline Reg & Data count & Flight count \\
\hline AC-01 & 924 & 7 \\
AC-02 & 1797 & 15 \\
AC-03 & 1720 & 13 \\
AC-04 & 1832 & 16 \\
AC-05 & 709 & 6 \\
AC-06 & 457 & 4 \\
AC-07 & 1172 & 9 \\
AC-08 & 369 & 3 \\
AC-09 & 2465 & 19 \\
AC-10 & 1552 & 13 \\
AC-11 & 1363 & 11 \\
AC-12 & 1320 & 10 \\
\hline Total & 15,680 & 126 \\
\hline
\end{tabular}

Aircraft mass, depending on ULF moment and payload, varies between 205.9 tonnes and 341.4 tonnes. This high variation in aircraft weight can be attributed to the flight direction, because westbound flights tend to be longer compared to eastbound flights, due to prevailing wind and therefore needs more trip fuel. Showing a normal distribution, the mean and median of aircraft mass during ULF is found to be 266.3 tonnes $(\mathrm{SD}=24.0)$ and 264.2 tonnes, respectively. The total fuel on board accounts for an average of $29.1 \%$ (ranging from $24.6 \%$ to $35.3 \%$ and with an $\mathrm{SD}=3.0 \%$ ) of total weight.

It is acknowledged that the weight of an aircraft is one of the most important factors affecting the fuel consumption of the aircraft. However, quantifying the effects of weight on fuel consumption can be difficult, since either other factors cannot be kept constant or these factors might mask the real influence of the weight. In addition to aircraft weight, cruise altitude is another important parameter affecting fuel consumption. Cruising at higher altitudes, providing there is suitable wind and sufficient range, generally results in less fuel consumption and shorter flight times [9].

In Figure 1a, the variation of FF with aircraft mass (ranging between 209 and 341 tonnes) is illustrated. Regardless of which altitude the cruise flight is performed at, it can be noted that the cruise FF varies monotonically between $0.8 \mathrm{~kg} / \mathrm{s}$ and $1.4 \mathrm{~kg} / \mathrm{s}$ for aircraft mass values throughout. While a number of observations for lower altitudes appear to be scattered all over the observation curve, it is noted that the observations for higher altitudes tend to concentrated at the lower part of the curve. 
Turgut / Anadolu Univ. J. of Sci. and Technology A-Appl. Sci. and Eng. $18(1)-2017$
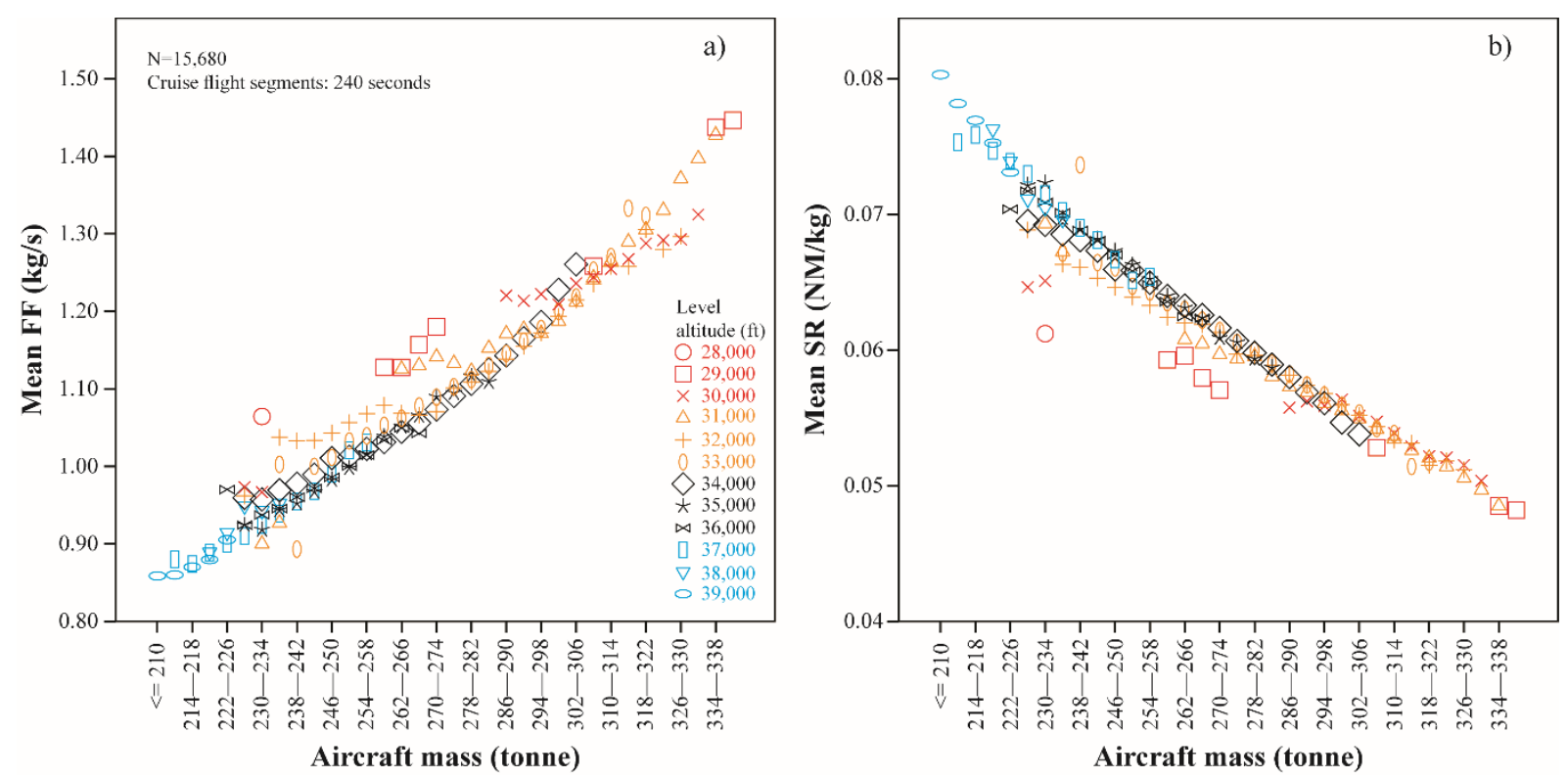

Figure 1. Variation of a) FF and b) Specific range (SR) with aircraft mass and level flight altitude (the vertical scales do not begin from zero in order to facilitate an understanding of trend)

Since FF values compromise flight speed, the effects of aircraft mass on specific range may also be investigated. Specific range is an important performance parameter and can be obtained from the following equation [10]:

$$
\text { Specific Range }=\frac{\mathrm{TAS}[\mathrm{knot}]}{\mathrm{FF}_{\mathrm{t}}[\mathrm{kg} / \mathrm{h}]}
$$

where specific range is given in $\mathrm{NM} / \mathrm{kg}$ and TAS and $\mathrm{FF}_{\mathrm{t}}$ denote true air speed and the sum of the fuel flow of the two engines. This parameter shows what distance can be flown by burning $1 \mathrm{~kg}$ of fuel. Since the effect of TAS has already been included, it also shows less variance compared to FF. According to Figure $1 \mathrm{~b}$, a linear relationship with aircraft mass is observed. The results suggest that each 4 tonnes of increment in aircraft mass results in a decrease in specific range at an average of $1.6 \%$. It should be noted that further discussion related to specific range will be provided in future studies.

\section{RESULTS AND DISCUSSION}

In this section, a dataset based on actual flight data is used to run regression analyses. In these analyses, the FF parameter is selected as a dependent variable. Bearing in mind that the dataset altitude changes between 29,000 ft and 39,000 ft, regression analyses are performed considering two approaches in the following paragraphs. First, three independent variables, altitude, aircraft mass and TAS, are selected and a single regression equation is developed. In the second approach, multiple regression equations are developed, one for each ULF, which add up to eleven equations. It should be noted that in these equations, the altitude parameter is removed from the independent variables. Aircraft mass, cruise altitude, TAS and FF parameters have been tested for normal distribution (with Skewness and Kurtosis coefficients) and all of the parameters are found to show normal distribution.

\subsection{First Approach}

First, a single regression equation for $\mathrm{FF}(\mathrm{kg} / \mathrm{s})$, based on three independent variables, altitude, aircraft mass and TAS, is developed as follows $\left(\mathrm{R}^{2}=0.940 ; \mathrm{SEE}=0.0245 ; \mathrm{F}=81,545 ; \mathrm{p}<0.01\right)$ :

$$
\mathrm{FF}=\left[-0.306-3.945 \times 10^{-6}(\text { Altitude })+6.585 \times 10^{-12}\left(\mathrm{Mass}^{2}\right)+2.157 \times 10^{-3}(\mathrm{TAS})\right] \times 2
$$


where the altitude ( $\mathrm{t}=-19.2)$ is in $f t$, aircraft mass $(\mathrm{t}=230.6)$ in $\mathrm{kg}$ and TAS $(\mathrm{t}=74.7)$ in knots. Based on $t$ values, the square of mass appears to have the strongest effect on FF, followed by TAS and altitude. A multiplier (2) is required for consideration of both engines. Here a question may arise as to whether TAS and altitude create a collinearity since generally the higher the altitude the higher is the flight speed, which indicates a potential relationship between two independent variables. The collinearity was examined with a variation inflation factor (VIF) with the VIF values being found to be between 1.09 and 3.60 for the independent variables. In addition, a correlation analysis was also performed between altitude and TAS with the correlation coefficient being found to be $-0.286(\mathrm{p}<0.01)$. These findings conclude that there is no collinearity symptom.

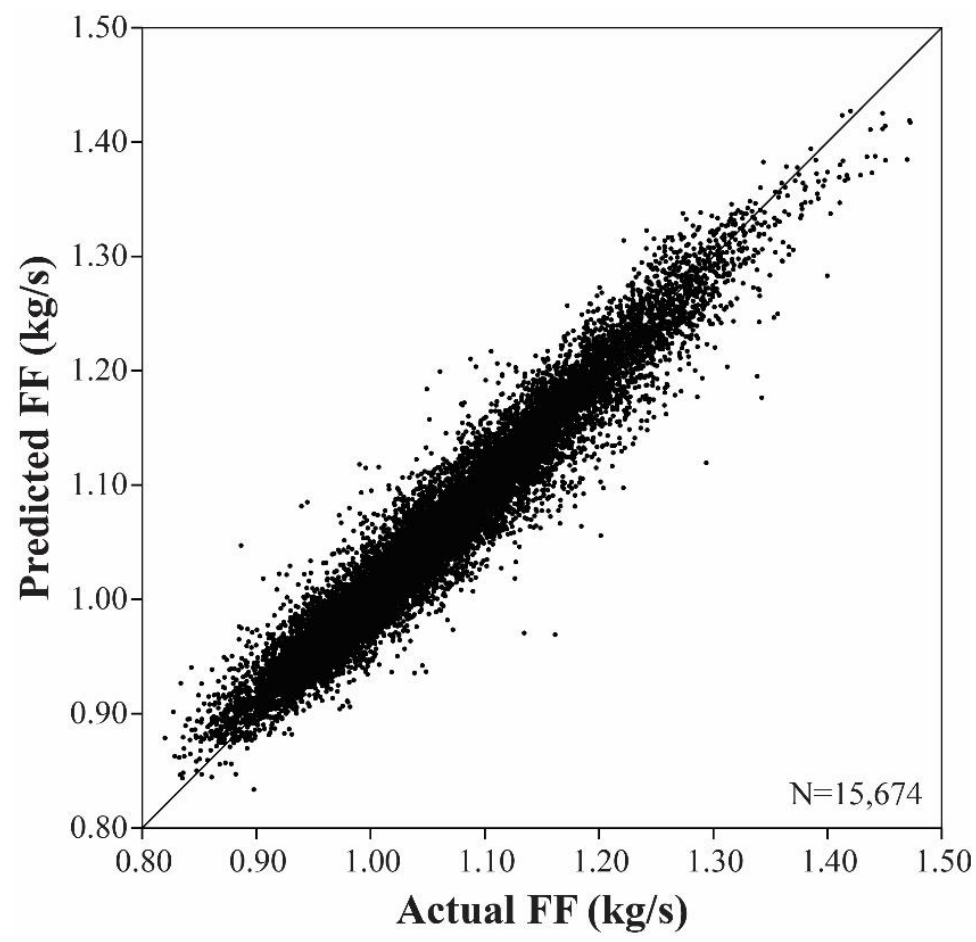

Figure 2. Comparison of the predicted and actual FF obtained by the first approach

Referring to Figure 2 and the statistical parameter provided above, it can be noted that predictors may be used to explain $94 \%$ of the variance in FF. The strength of the equation may be understood better if the ratio of the residuals to the actual FF is examined. Analyses show that the average of the ratio of the residual to the actual FF is found to be $1.7 \%$, whereas the residual percentage of $90 \%$ for all of the observations is observed to be in the range of $\pm 3.7 \%$. This implies that errors caused by the regression equation appear to be mainly negligible.

However, in Figure 2, the relationship does not express the effects of altitude and, therefore, it is difficult to assert whether there are any altitude categories in which these regression equation estimations are better or worse than others. This effect can be discussed further with Figure 3, where the equation results are indicated with individual altitude categories. While the accuracy of the regression equation seems to be relatively weaker at lower altitudes and aircraft mass categories, it may be noted that this result most likely appears due to very few observations at these categories. For instance, the average observation numbers for the top $10 \%$ of the differences between predicted and actual FF is just 6 , with an average of difference value of $0.043 \mathrm{~kg} / \mathrm{s}(3.9 \%)$. In the meantime, for other parts of the dataset (the remaining 90\%), where the differences between predicted and actual FF appears much lower, the average observation number is 115 , with an average difference of $0.008 \mathrm{~kg} / \mathrm{s}(0.8 \%)$. Obviously, while the low number of observations cannot be considered to be a single reason why the regression equation cannot 
fully explain the dataset at lower altitudes and mass categories, as it does for the main part of the dataset, there is every reason to suppose better explanation of these categories when there are more observations. This case will be discussed more fully in the next section.

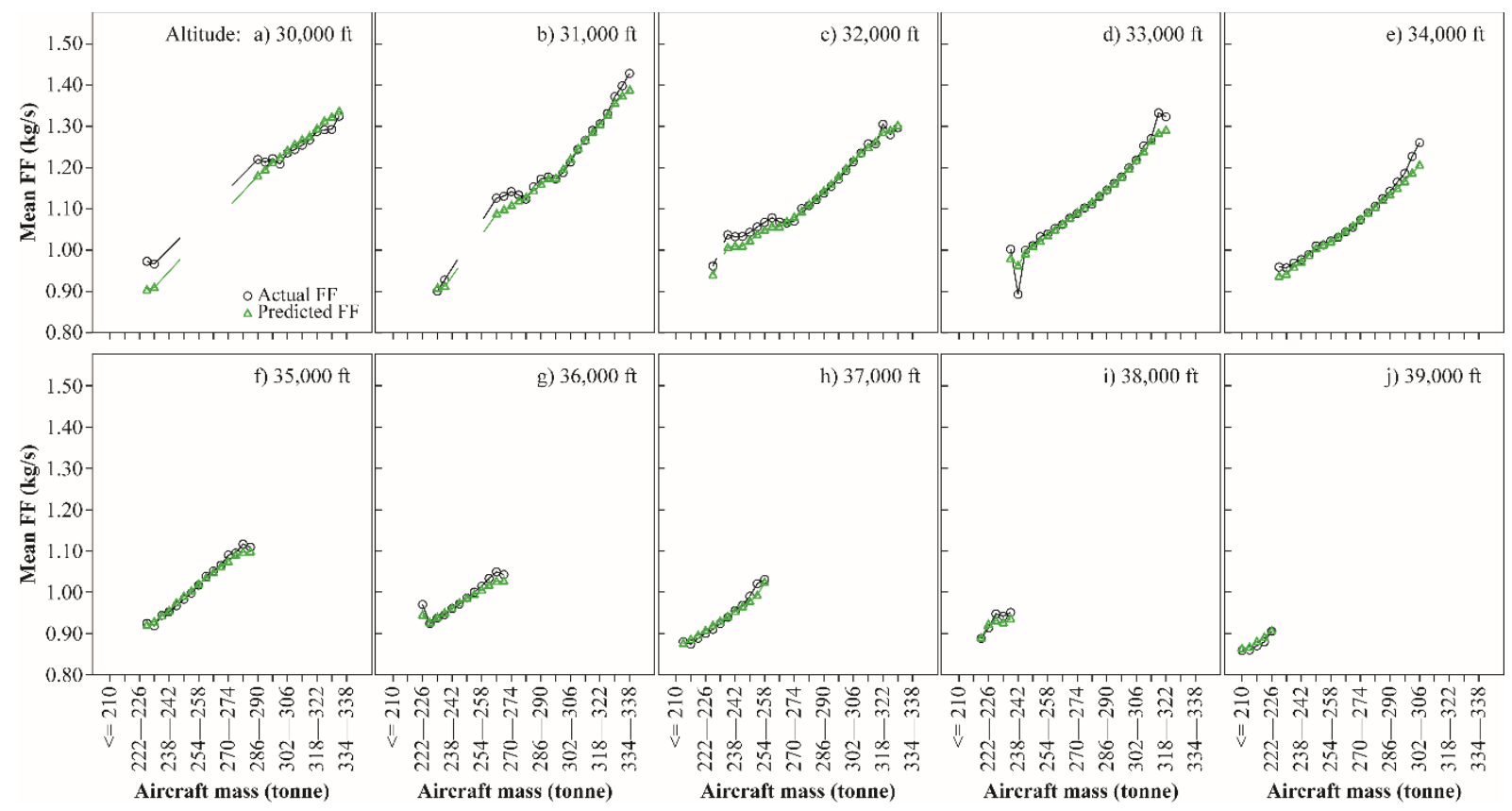

Figure 3. Comparison of predicted and actual FF with altitude (a-j) and aircraft mass categories

\subsection{Second Approach}

In the second approach, this time one of the predictors, the altitude, has been removed from the independent variable list and theregression analyses are performed individually for each of the altitude categories. The altitude categories are separated by thousands of $f t$. Therefore, there are eleven regression equations and each equation is limited by the ULFs at certain altitude levels. The equations and related statistical parameters are provided in Table 2, and a comparison of predicted and actual FF is shown in Figure 4. The regression equations appear to explain most of the observations, particularly up to $38,000 \mathrm{ft}$ of altitude, however, in the last two altitude categories they have considerably low $\mathrm{R}^{2}$. The reason for this result has been investigated further. One symptom, which is noticed at the beginning, is that the observation numbers at these altitude categories are low, and a lower determination coefficient can be justified by the lower number of observations. However, the regression equations developed for $29,000 \mathrm{ft}$ of altitude, for which the observation numbers are lowest, or for 30,000 and 31,000 ft of altitudes, where the observation numbers are relatively lower compared to higher altitude categories, do not seem to verify this argument. Nonetheless, aircraft mass distribution over ULFs reveals that in the last two altitude categories, the aircraft mass values are concentrated in a limited mass range of 218-238 tonnes at 38,000 ft and lower than 226 tonnes at 39,000 ft. This is meaningful because these cruise altitudes are generally seen during the last segments of the cruise and, at these highest altitudes, the aircraft have already burned a major portion of the fuel in board which makes aircraft flying at this altitude to exhibit closer aircraft mass values to each other by converging to a zero fuel weight. When considering the lower altitudes $(29,000-31,000 \mathrm{ft})$, it can be seen that aircraft mass is more evenly distributed. Therefore, the reduction in strength of the regression models at very high altitudes can be attributed to a limited observation distribution of one of the independent variables, aircraft mass, rather than the low number of observations. 
Turgut / Anadolu Univ. J. of Sci. and Technology A-Appl. Sci. and Eng. $18(1)-2017$

Table 2. Results of regression analyses by the second approach (mass in kg and TAS in knot)

\begin{tabular}{llllllll}
\hline Altitude & $\mathbf{N}$ & $\mathbf{R}^{\mathbf{2}}$ & SEE & $\mathbf{F}$ & \multicolumn{2}{l}{ Coefficients } & \\
\cline { 5 - 8 } & & & & & Constant & Mass square & TAS \\
\hline 29,000 & 29 & 0.981 & 0.018 & 751 & -1.277 & $5.225 \times 10^{-12}$ & $4.235 \times 10^{-3}$ \\
30,000 & 329 & 0.830 & 0.024 & 804 & -0.343 & $5.139 \times 10^{-12}$ & $2.265 \times 10^{-3}$ \\
31,000 & 404 & 0.931 & 0.024 & 2708 & -0.887 & $5.855 \times 10^{-12}$ & $3.255 \times 10^{-3}$ \\
32,000 & 2540 & 0.840 & 0.025 & 6684 & -0.606 & $6.130 \times 10^{-12}$ & $2.599 \times 10^{-3}$ \\
33,000 & 2518 & 0.786 & 0.025 & 4622 & -0.533 & $6.512 \times 10^{-12}$ & $2.372 \times 10^{-3}$ \\
34,000 & 3319 & 0.811 & 0.024 & 7136 & -0.473 & $6.841 \times 10^{-12}$ & $2.191 \times 10^{-3}$ \\
35,000 & 2743 & 0.744 & 0.025 & 3983 & -0.253 & $7.651 \times 10^{-12}$ & $1.611 \times 10^{-3}$ \\
36,000 & 2100 & 0.660 & 0.020 & 2042 & -0.321 & $7.741 \times 10^{-12}$ & $1.749 \times 10^{-3}$ \\
37,000 & 1471 & 0.677 & 0.021 & 1543 & -0.414 & $7.928 \times 10^{-12}$ & $1.917 \times 10^{-3}$ \\
38,000 & 105 & 0.372 & 0.032 & 32 & -1.198 & $1.157 \times 10^{-11}$ & $3.182 \times 10^{-3}$ \\
39,000 & 120 & 0.451 & 0.020 & 50 & -0.428 & $6.642 \times 10^{-12}$ & $2.070 \times 10^{-3}$ \\
\hline
\end{tabular}

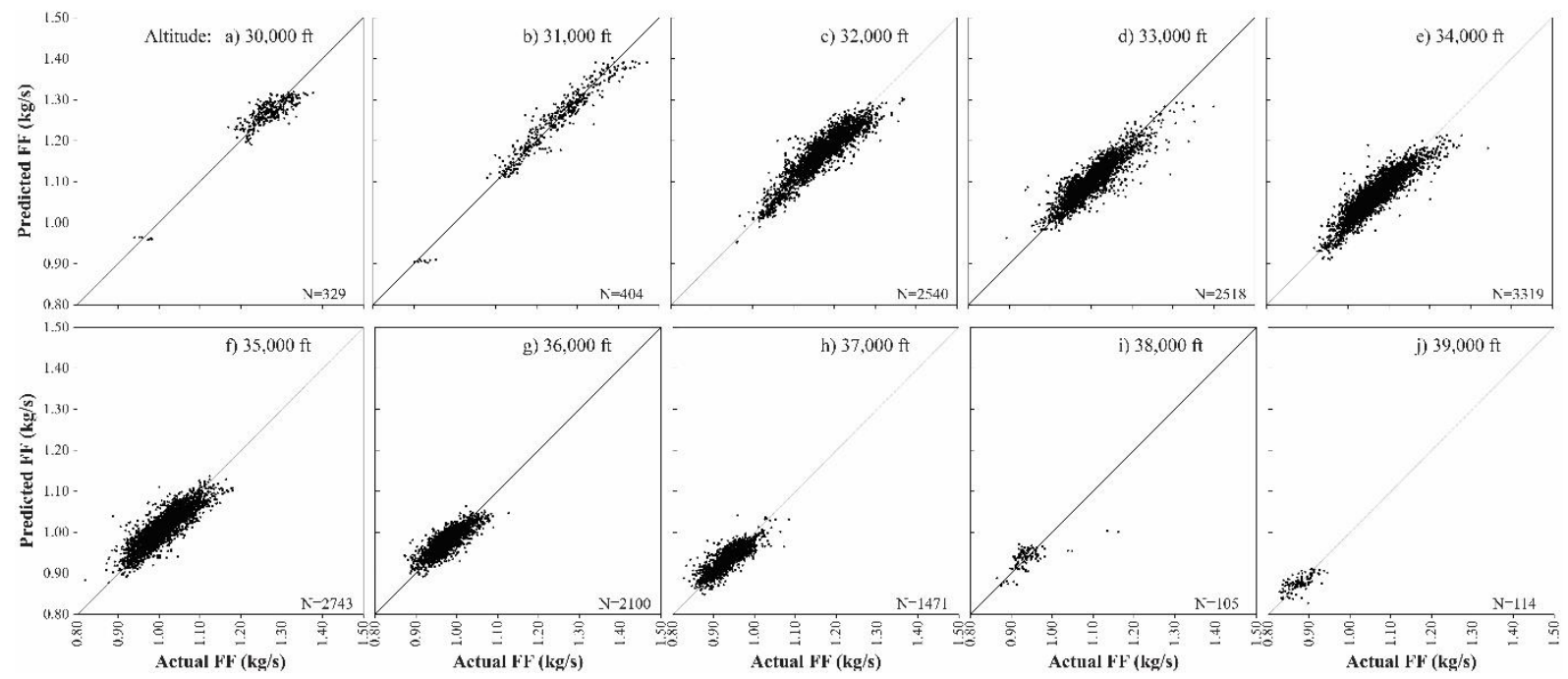

Figure 4. Comparison of the predicted and actual FF, with altitude (a-j), obtained by the second approach

When a residual analysis is run for the second approach, similar results to the results for the first approach are obtained. The average of the ratio of the residuals to actual FF are about $\pm 1.7 \%$, and this ratio is found in the $\pm 3.6 \%$ range for $90 \%$ for all the observations. The highest average of this ratio is found for $38,000 \mathrm{ft}$ of altitude to be $\pm 2.2 \%$.

From the results of first and second approach, in terms of residual analysis, only at 30,000 ft of altitude is the average of the ratio of the residual to actual FF values found to be relatively higher for first approach. Above this altitude, the results of the first approach converge to those for the second approach. Nonetheless, it should be noted that though the results of the first approach appear to be relatively higher than they do for the second approach, the amount of the error for both approaches is so small that it can be considered to be negligible.

\subsection{Fuel Effect of Non-Payload Weight}

In this section, regression equations (both approaches) are used to calculate the effects of non-payload weight on FF. The findings of these analyses help in an understanding of the fuel cost of the non-payload or unnecessary weight of equipment or excess fuel. Basically, the objective of this section is to find how much fuel is needed to carry $100 \mathrm{~kg}$ of mass. 
The analyses method can be described as follows. The effects of aircraft mass on FF are investigated at each altitude category separately. In addition, the range of aircraft mass and mean TAS are also considered by the corresponding altitude category. For instance, the aircraft mass varies between 260341 tonnes at 29,000 ft, whereas it varies between 228-302 tonnes at 34,000 ft. The mean TAS at the given example altitudes are 489 knots and 477 knots, respectively. Therefore, the results of each altitude category involves values of the other two independent variables inherent to the related altitude category. For each of the altitude categories, the regression equation runs for a one hour flight and the aircraft mass variable in the equation is tuned each second due to mass reduction caused by fuel burn. Due to particularly long cruise flights, since aircraft mass varies considerably, the effects of aircraft mass on FF differ. Therefore, for a precise calculation, one should include the reduction in aircraft mass during an ULF.

The analyses results for the first approach show that carrying an additional $100 \mathrm{~kg}$ of payload affects the fuel burn of a one hour cruise flight at an average of about $2.56 \mathrm{~kg}$, regardless of altitude. These averages change between a minimum of $2.11 \mathrm{~kg}$ and a maximum of $3.01 \mathrm{~kg}$, depending on initial aircraft mass. The main difference between minimum and maximum value is due to the aircraft initial mass, which implies that as the aircraft initial mass increases, the effect of extra payload on fuel burn also increases. In addition, it should be noted that a ULF altitude change does not affect the 'influence of the cost of carrying $100 \mathrm{~kg}$ of extra payload on FF' significantly. Investigating the TAS changes on the 'influence of carrying $100 \mathrm{~kg}$ of extra payload on FF' also reveals negligible effects, of which for instance, increasing and decreasing TAS by $20 \%$ at corresponding altitudes results in a $0.4 \%$ decrease and an increase being an average of extra fuel burn value of 2.55 and $2.57 \mathrm{~kg}$, respectively.

The analyses for the second approach result in slightly different outputs. The average fuel cost of carrying $100 \mathrm{~kg}$ of payload is again found to be $2.55 \mathrm{~kg}$. However, with this approach, it ranges from between 2.03 and 3.07 at 29,000 ft and 37,000 ft of altitudes, respectively. In other words, unlike the first approach, this time the ULF appears to significantly affect the cost of carrying $100 \mathrm{~kg}$ of payload. Regarding the effect of initial aircraft mass, it should be noted that the difference between the minimum and the maximum initial aircraft mass (for the corresponding altitude category) can be around $1 \%$ (ranging from between $0.71 \%$ and $1.07 \%$ due to ULF), which is close to that found for the first approach $(0.9 \%)$. However, the difference is that in the former, the percentages are constant for different ULFs, yet in the latter, they increase with increasing ULFs.

The analyses on two approaches conclude that carrying $100 \mathrm{~kg}$ of extra payload leads to a burning of 2$3 \mathrm{~kg}$ of fuel per hour. In other words, for every $\mathrm{kg}$ of payload, an amount of fuel that is $2-3 \%$ of its weight is burned per hour, with this amount depending on ULF and initial aircraft mass. In order to fully understand the importance of the effects of aircraft mass on fuel cost two illustrative examples can be discussed. However, first, a typical utilization average (time spent airborne) of aircraft featured in this paper is required. According to a report by Eurocontrol, the utilization of aircraft on average is around 14 hours per day, which equals to 5110 hours per year [11].

In this regard, we can see that considering an extreme case, in which carrying an unnecessary washer or a rivet weighing 50 grams results in $6.4 \mathrm{~kg}$ of additional fuel burn annually (fuel used being of $2.5 \%$ of additional mass). The example may be extended with consideration of heavier dispensable cabin furniture, hardcopy books or manuals, magazines, catering menu items or even extra fuel and so on. For instance, in new generation aircraft, laptops or tablets are being used, rather than much heavier flight manuals or technical logbooks. Therefore, improper planning of aircraft non-payload or passenger onboard service items, regardless of how lightweight they are, likely impair fuel consumption.

Another illustrative example can be given with aircraft paintwork. According to Boeing, decorative painting around the fuselage (upper and lower half of fuselage and tail with customer markings) of an aircraft, used in these analyses, with paints of $0.1 \mathrm{~mm}$ thicknesses results in $215.5 \mathrm{~kg}$ of additional mass 
[12]. Instead of painting the fuselage, polishing the skin of the fuselage and keeping the customer airline marks weighs only $24.9 \mathrm{~kg}$ and the difference in aircraft mass of the two approaches is found to be 190.6 $\mathrm{kg}(215.5-24.9)$. Therefore, bearing in mind that assumptions may be within a large tolerance, the annual fuel burn and fuel cost of carrying paint can be calculated at 19,479 $\mathrm{kg}$ (being fuel used for $2 \%$ of paint mass) or $29,218 \mathrm{~kg}$ (being fuel used for $3 \%$ of paint mass) of fuel, which corresponds to 11,038 USD or 16,557 USD per annual, respectively (1.70 USD per gallon of Jet A1 with all of the results being given for a single aircraft). Obviously, effects of this order are not only serious in terms of fuel cost, but also from an environmental impact viewpoint. Therefore, it would be plausible to suppose that tonnes of carbon dioxide and other harmful emissions to a lesser extent may be avoided by applying nanotechnology coating, at less than micron-thick.

\section{CONCLUSION}

To increase the efficiency of any system the key step is to minimize losses within the system and its components. In this regard, the current aviation system possesses great fuel saving potential and one practical way is to minimize the non-payload weight of an aircraft. Carrying one $\mathrm{kg}$ of unnecessary mass does not seem to account for significant fuel cost, however, evaluated with a cumulative cost through the total service life of an aircraft, and with diminishing oil reserves, the cost of this loss may be considerably high.

In this study, intercontinental flights performed by wide-ranged aircraft are investigated in order to quantify the fuel cost of non-payload aircraft weight and to address how much fuel can be saved. Based on actual flight data records, regression equations are developed where fuel flow is the independent variable with altitude, aircraft initial mass and true air speed being dependent variables. It is concluded that for every $1 \mathrm{~kg}$ of non-payload aircraft mass there is an increment in fuel consumption of about 2$3 \%$ of the non-payload mass, and this percentage is positively correlated with initial aircraft mass and true air speed.

\section{REFERENCE}

[1] Filippone A. Comprehensive analysis of transport aircraft flight performance. Prog. Aerosp. Sci 2008; 44: 192-236. doi:10.1016/j.paerosci.2007.10.005.

[2] Fokker Services Supplement to "IATA, Guidance Material and Best Practices for Fuel and Environmental Management”. Fokker, Fuel and Environmental Management. 2010.

[3] Fan W, Sun Y, Zhu T, Wen Y. Emissions of $\mathrm{HC}, \mathrm{CO}, \mathrm{NOx}, \mathrm{CO}_{2}$, and $\mathrm{SO}_{2}$ from civil aviation in China in 2010. Atmos. Environ 2012; 56: 52-57.

[4] Clarke JP, Brooks J, Nagle G, Scacchioli A, White W, Liu SR. Optimized profile descent arrivals at Los Angeles International Airport, Journal of Aircraft 2013; 50: 360-369. doi:10.2514/1.C031529.

[5] Lathasree P, Sheethal RM. Estimation of aircraft fuel consumption for a mission profile using neural networks. In: Proceedings of the International Conference on Aerospace Science and Technology 2008, INCAST 2008-115.

[6] Pham VV, Tang J, Alam S, Lokan C, Abbass HA. Aviation emission inventory development and analysis, Environ. Model. Softw 2010; 25: 1738-1753. doi:10.1016/j.envsoft.2010.04.004.

[7] Vera-Morales M, Hall C. Modeling performance and emissions from aircraft in the aviation integrated modelling project. Journal of Aircraft 2010; 47: 812-819. doi:10.2514/1.44020. 
Turgut / Anadolu Univ. J. of Sci. and Technology A-Appl. Sci. and Eng. $18(1)-2017$

[8] Zhu Y, Fanning E, Yu RC, Zhang Q, Froines JR. Aircraft emissions and local air quality impacts from takeoff activities at a large International Airport. Atmos. Environ 2011; 45: 6526-6533. doi:10.1016/j.atmosenv.2011.08.062.

[9] Schoemig EG, Boyle DA, Scharl J, Haraldsdottir A. Descent profile options for continuous descent arrival procedures within 3d path concept. In: IEEE/AIAA 26th Digit. Avion. Syst. Conf; 2007; Dallas, TX, USA: 3.A.3-1-3.A.3-11. doi:10.1109/DASC.2007.4391872.

[10] Padilla CE. Optimizing Jet Transport Efficiency: Performance, operations and economics. 1st ed. McGraw-Hill, 1996.

[11] Eurocontrol Central Office for Delay Analysis, Study into the impact of the global economic crisis on airframe utilization, 2011(https://www.eurocontrol.int/sites/default/files/content/documents /official -documents/facts-and-figures/coda-reports/study-impact-global-economic-crisis-2011.pdf)

(Access: May 21, 2016)

[12] http1:http://www.boeing.com/commercial/aeromagazine/aero_05/textonly/fo01txt.html (Access: May 21, 2016) 